Journal of Current and Advance Medical Research

Editorial

\title{
Environmental Pollution and Health Hazards: Present and Future Perspective of Bangladesh
}

\author{
AFM Arshedi SATTAR \\ Assistant Professor, Department of Microbiology, National Institute f Neurosciences \& Hospital, Sher-E-Bangla \\ Nagar, Agargaon, Dhaka-1207, Bangladesh; Email: afmasattar@yahoo.com; Cell no.: +8801611109942
}

Huge environmental pollution is reaching worrying proportions worldwide ${ }^{1}$. The massive increase in emissions of air, soil and water pollutants due to economic and industrial growth in the last century made air, soil and water quality an environmental problem of first order in a large number of developing country like Bangladesh ${ }^{2}$. Currently it is established as an emerging problem in other regions of the world as well ${ }^{3}$. According to the World Health Organization (WHO), about one-third of disease burden is contributed by environmental hazards ${ }^{4}$. Urbanization and industrialization along with economic development have led to increase in energy consumption and waste discharges. The global environmental pollution, including greenhouse gas emissions and acid deposition, as well as water pollution and waste management is considered as international public health problems, which should be investigated from multiple perspectives including social, economic, legislation, and environmental engineering systems, as well as lifestyle habits helping health promotion and strengthening environmental systems to resist contamination $^{5-7}$.

Different pollutants of the environmental causes various adverse health effects beginning from very early in life of which the most important harmful effects are perinatal disorders, infant mortality, respiratory disorders, allergy, malignancies, cardiovascular disorders, increase in stress oxidative, endothelial dysfunction, mental disorders, and various other harmful effects ${ }^{8-9}$. In majority of time immediate effects of environmental pollutants are usually stressed; however, wide range of hazards of air pollution from early life and their possible implication on chronic noncommunicable diseases of adulthood should be underscored $^{1}$. Environmental particulate exposure has been linked to increased risk of morbidity and mortality from many diseases, organ disturbances, cancers, and other chronic diseases ${ }^{10-11}$. Therefore it is time to take action and control the pollution. Otherwise, the waste products from consumption, heating, agriculture, mining, manufacturing, transportation, and other human activities will degrade the environment.

There are many major attributable risk factors causing environmental disease burden and increase health hazards in this subcontinent ${ }^{4}$. These traditional environmental health hazards are lack of access to safe drinking water, indoor air pollution from solid fuel combustion, and lack of sanitation and hygiene ${ }^{8}$. In addition to that there is a notable economic growth in the past decade due to urbanization and industrialization which lead to modern environmental health hazards (MEHHs) ${ }^{11}$. These perhaps supersede traditional hazards as critical contributors to environmental disease burden in the continent. Traditional health hazards and risks should be managed which will provide the future better world.

MEHHs are products of rapid development in the absence of health and environment safeguards, as well as the unsustainable consumption of natural resources ${ }^{11}$. MEHHs include water pollution from populated areas 
and industry, urban air pollution from automobiles, radiation hazards, land degradation, climate change, and emerging and reemerging infectious diseases ${ }^{10}$. In Bangladesh there is lack of waste disposal processing plant in the industries which lead to environmental pollution. All the wastes are deposited in the soil, mixes with water and air. Therefore, the environment of this country becomes an unfavorable for future generation.

The increasing significance of MEHHs is now a public health issue in Bangladesh. The presence of development-related activities capable of generating these hazards; evidence of the occurrence of these types of hazards in environmental media as a result of development activities; evidence of human exposure to some of these hazards; and evidence of adverse effects among Bangladeshi populations. Chemical-specific pollutants are toxics from industrial activity, air pollution from automobiles, and pesticides from modern agricultural practices ${ }^{8}$. Chemical hazards is solely based on the relative preponderance of data for these types of hazards and is therefore very narrow in terms of the scope of possible MEHHs that are products of development.

[Cited as: Sattar AFMA. Environmental Pollution and Health Hazards: Present and Future Perspective of Bangladesh. J Curr Adv Med Res, 2014;1(1):1-2]

\section{References}

1. Kelishadi R. Environmental Pollution: Health Effects and Operational Implications for Pollutants Removal. Journal of Environmental and Public Health; 2012; 2012: 341637
2. Nweke OC, Sanders Iii WH. Modern environmental health hazards: a public health issue of increasing significance in Africa. Environmental health perspectives 2009; 117(6): 863-870

3. Shea KM, Truckner RT, Weber RW, Peden DB. Climate change and allergic disease. J Allergy Clin Immunol 2008, 122(3):443-453

4. Pruss-Ustün A, Bonjour S, Corvaln C. The impact of the environment on health by country: a meta-synthesis. Environmental Health 2008; 7(7): 1-10

5. Loux NT, Su YS, Hassan SM. Issues in assessing environmental exposures to manufactured nanomaterials. Intern $\mathrm{J}$ Environ Res Public Health 2011;8(9):3562-3578

6. Abbasi T, Abbasi SA. Water quality indices based on bio-assessment: the biotic indices. J Water Health 2011;9(2):330-348

7. Kelishadi R, Mirghaffari N, Poursafa P, Gidding SS. Lifestyle and environmental factors associated with inflammation, oxidative stress and insulin resistance in children. Atherosclerosis. 2009;203(1):311-319

8. Kelishadi R, Poursafa P. Air pollution and nonrespiratory health hazards for children. Archives of Medical Science, 2010;6(4):483495

9. Kelishadi R, Mirghaffari N, Poursafa P, Gidding SS. Lifestyle and environmental factors associated with inflammation, oxidative stress and insulin resistance in children. Atherosclerosis, 2009;203(1):311-319

10. Kargarfard M, Poursafa P, Rezanejad S, Mousavinasab F. Effects of exercise in polluted air on the aerobic power, serum lactate level and cell blood count of active individuals. International Journal of Preventive Medicine, 2011;2(3):145-150

11. Coogan PF, White LF, Jerrett $M$, et al. Air pollution and incidence of hypertension and diabetes mellitus in black women living in los angeles. Circulation, 2012;125(6):767-772 